\title{
The significance of programmed cell death ligand 1 expression in resected lung adenocarcinoma
}

\author{
Shafei Wu ${ }^{1, *}$, Xiaohua Shi ${ }^{1, *}$, Jian Sun ${ }^{1}$, Yuanyuan Liu ${ }^{1}$, Yufeng Luo ${ }^{1}$, Zhiyong \\ Liang ${ }^{1}$, Jinghui Wang ${ }^{2}$, Xuan Zeng ${ }^{1}$ \\ ${ }^{1}$ Department of Pathology, Peking Union Medical College Hospital, Beijing, China \\ ${ }^{2}$ Department of Medical Oncology, Beijing Tuberculosis and Thoracic Tumor Research Institute, Beijing Chest Hospital, Capital \\ Medical University, Beijing, China \\ *These authors are co-first authors
}

Correspondence to: Xuan Zeng, email: zengxuan88@yahoo.com

Keywords: lung adenocarcinoma, programmed cell death ligand 1, immunohistochemistry, in situ hybridization

Received: October 11, 2016

Accepted: January 16, 2017

Published: January 27, 2017

\section{ABSTRACT}

Background: Lung adenocarcinoma (AD) is a common variant of non-small cell lung cancer (NSCLC). Programmed cell death protein 1/programmed cell death ligand 1 (PD1/PD-L1) are promising immunotherapy targets and its expression may be an important biomarker of predicting clinical response. In this study, we evaluated PDL1 expression in conjunction with clinicopathological characteristics and outcomes in resected lung adenocarcinoma.

Results: This study included 133 cases of lung adenocarcinoma. PD-L1 expression rate in lung adenocarcinoma was $16.5 \%$ at the mRNA level and $13.5 \%$ at the protein level, and the kappa coefficient of the two examination methods was $0.824(P=0.219$, highly correlated). PD-L1 was highly expressed in male patients and smokers with lung adenocarcinoma $(P=0.019$ and 0.002 , respectively), while no associations were identified between PD-L1 expression and age, tumor size, clinical stage, positive pleural invasion, lymph node metastasis, or therapy methods. Overexpression of PD-L1 was a significant indicator of shorter recurrence free survival time and overall survival ( $P=\mathbf{0 . 0 0 0}$ and $\mathbf{0 . 0 0 0}$, respectively). Multivariate analysis revealed that PDL1 expression was an independent risk factor for poor recurrence free survival and overall survival ( $P=0.009$ and 0.016 , respectively).

Materials and Methods: Expression of PD-L1 was examined with immunohistochemistry, using the VENTANA PD-L1 (SP263) rabbit monoclonal antibody. mRNA levels of PD-L1 were evaluated using in situ hybridization.

Conclusions: PD-L1 overexpression is more frequently observed in male patients and smokers in lung adenocarcinoma. PD-L1 expression is an indicator of worse prognosis in surgically resected lung adenocarcinoma patients.

\section{INTRODUCTION}

Lung adenocarcinoma is a common variant of nonsmall cell lung cancer (NSCLC). In recent years, there have been dramatic advances in the treatment of lung adenocarcinoma because of the development of therapies targeting driver oncogene alterations, for example, drugs targeting the epidermal growth factor receptor (EGFR) mutation or the anaplastic lymphoma kinase (ALK) fusion $[1,2]$. However, most patients will inevitably develop acquired resistance to the targeted therapy [3-5]. Therefore, exploration into new lung cancer treatments is ongoing. Recently, immune check-point inhibition therapy has shown promising results in several kinds of malignant tumors, including NSCLC [6].

Immune checkpoints are inhibitory pathways that can maintain self-tolerance and protect peripheral tissues by modulating immune response [7]. Overexpression 
of immune checkpoint proteins in tumor cells or tumorinfiltrating lymphocytes (TILs) can help tumor cells escape surveillance by the immune system. Immune checkpoint inhibitor therapy can block the ligand- receptor interaction and activate a $\mathrm{T}$ cell immune response to attack the tumor cells. Programmed cell death protein 1/ programmed cell death ligand 1 (PD-1/PD-L1) is a major immune checkpoint signaling pathway. The binding of PD-L1 to PD-1 can block the immune response of T cells to the tumor cells. There are several ongoing clinical trials targeting NSCLC with PD-L1 protein. Pre-released data has shown that in unselected patients treated with antiPD-1/PD-L1 antibodies, roughly $20 \%$ had a meaningful response to therapy [8]. PD-L1 protein expression is reported to be a potential predictor of therapy response [9]. Careful selection of the specific population who will benefit from the targeted therapy is urgent. There are several commercial immunohistochemical (IHC) antibodies that have been designed as accompanying diagnostic tools for different clinical trials. However, owing to diverse examination methods and cutoff values, a unified standard examination method is needed for the selection of suitable targeted populations.

In this study, we evaluated PD-L1 expression using immunohistochemistry at the protein level and by in situ hybridization at the mRNA level. Furthermore, we compared the expression of PD-L1 with clinicopathological characteristics and outcomes in lung adenocarcinoma.
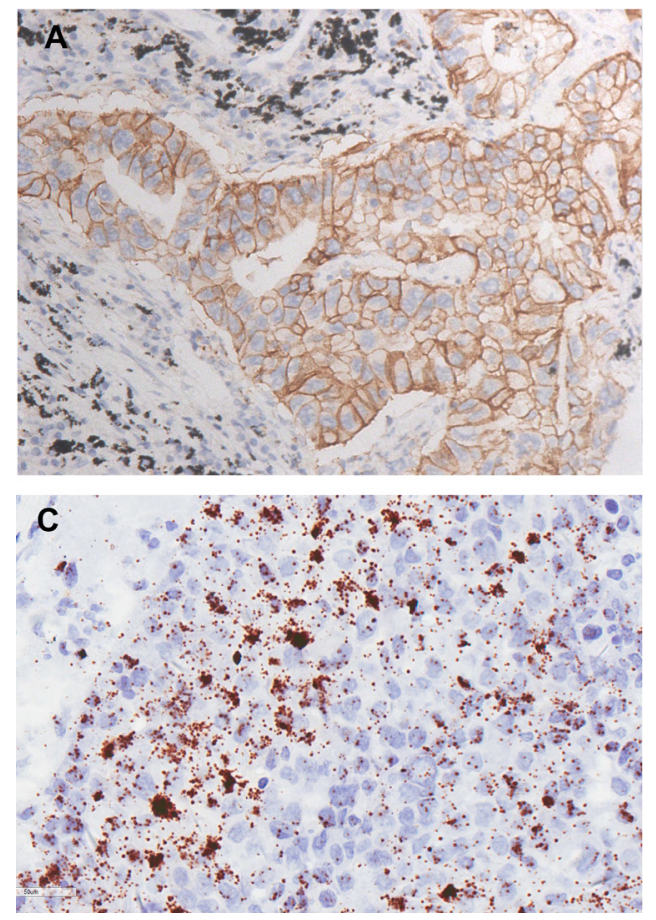

\section{RESULTS}

\section{Clinicopathological characteristics of lung adenocarcinoma}

The clinicopathological characteristics of the lung adenocarcinoma patients are summarized in Table 1. The median age was 58.94 years old (range, 32-84). Fifty-three $(39.8 \%)$ patients were male and 80 were female. Ninetyseven $(74.0 \%)$ had never smoked and 34 were smokers. The average tumor size was $3.2 \mathrm{~cm}$ (range, 1.5-7.0 cm). Tumors of stages I, II, III, and IV were observed in $65(48.9 \%), 16(12.0 \%), 42(31.6 \%)$, and 10 (7.5\%) cases, respectively. Post-operative therapy was performed in 65 patients: 64 patients received chemotherapy; 6 were exposed to radiation therapy, and 5 received both types of therapy.

The growth pattern of lung adenocarcinoma was classified into lepidic (16 tumors), acinar (65), mucinous (8), solid (18), papillary (19), and micropapillary (7) patterns. Pleural involvement was identified in 92 cases. Positive node metastasis was present in 53 cases.

\section{Comparison of PD-L1 expression examined by immunohistochemistry and RNA in situ hybridization methods}

Of the 133 cases of lung adenocarcinoma examined in this study, the PD-L1 expression rate in
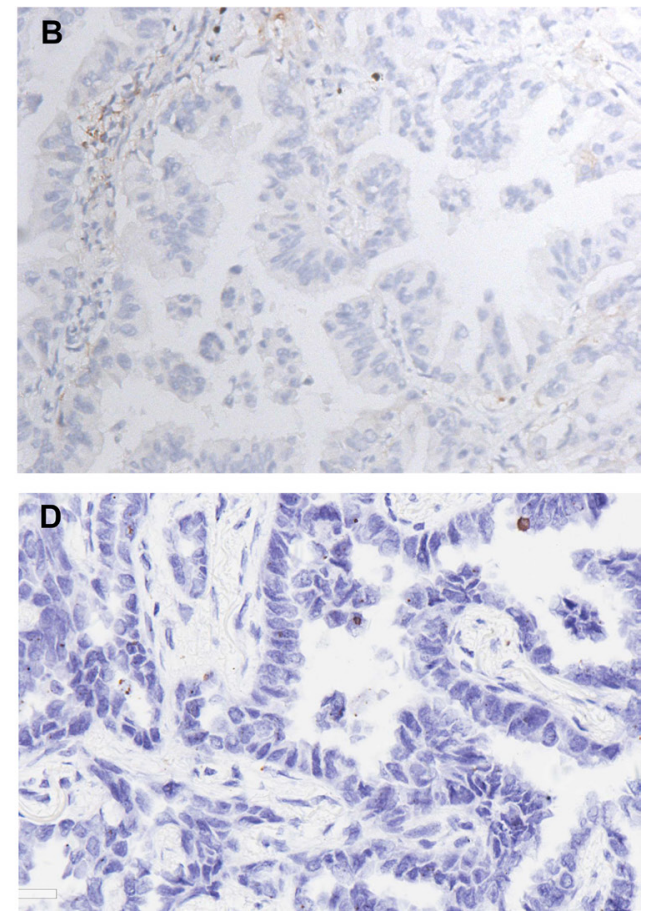

Figure 1: Representative results of PD-L1 expression in lung adenocarcinoma. (A) Positive result of PD-L1 examined via immunohistochemistry method. $(\times 40)$ (B) Negative result of PD-L1 examined via immunohistochemistry method. $(\times 40)$. (C) Positive result of PD-L1 examined via RNA in situ hybridization method. (×40). (D) Negative result of PD-L1 examined via RNA in situ hybridization method. $(\times 40)$ 
Table 1: Relationship between PD-L1 IHC expression and clinicopathological characteristics of lung adenocarcinoma patients

\begin{tabular}{|c|c|c|c|c|}
\hline \multirow{2}{*}{$\begin{array}{l}\text { Characterisitcs } \\
\qquad(N=133)\end{array}$} & \multirow{2}{*}{ No. of patients (Percentage) } & \multicolumn{3}{|c|}{ PD-L1 IHC } \\
\hline & & Positive $(N=18)$ & Negative $(N=115)$ & $p$-value \\
\hline Age & & & & \\
\hline$>=70$ & $39(29.3 \%)$ & 5 & 34 & 1.000 \\
\hline$<70$ & $94(70.7 \%)$ & 13 & 81 & \\
\hline Gender & & & & \\
\hline Female & $80(60.2 \%)$ & 6 & 74 & 0.019 \\
\hline Male & $53(39.8 \%)$ & 12 & 41 & \\
\hline Smoking* & & & & \\
\hline Smokers & $34(26.0 \%)$ & 10 & 24 & 0.002 \\
\hline Non- smokers & $97(74 \%)$ & 7 & 90 & \\
\hline Tumor Size (cm) & & & & \\
\hline$>3$ & $53(39.8 \%)$ & 6 & 47 & 0.613 \\
\hline$<=3$ & $80(60.2 \%)$ & 12 & 68 & \\
\hline Stage & & & & \\
\hline Early (I-II) & $81(60.9 \%)$ & 7 & 74 & 0.067 \\
\hline Advanced (III-IV) & $52(39.1 \%)$ & 11 & 41 & \\
\hline Invasion of pleural $^{* *}$ & & & & \\
\hline Yes & $92(70.2 \%)$ & 14 & 78 & 0.553 \\
\hline No & $39(29.8 \%)$ & 4 & 35 & \\
\hline Node metastasis & & & & \\
\hline Yes & $53(39.8 \%)$ & 9 & 44 & 0.439 \\
\hline No & $80(60.2 \%)$ & 9 & 71 & \\
\hline Histological subtype & & & & \\
\hline Acinar+lepdic & $81(60.9 \%)$ & 4 & 77 & 0.000 \\
\hline Others & $52(39.1 \%)$ & 14 & 38 & \\
\hline
\end{tabular}

Abbreviations: AD, adenocarcinoma; PD-L1, programmed cell death ligand 1; IHC, immunohistochemistry.

*Two patients lost of follow-up; **Two patients lost of follow-up.

lung adenocarcinoma detected by IHC and ISH was $13.5 \%(18 / 133)$ and $16.5 \%(22 / 133)$, respectively. The two techniques were consistent in identifying 110 cases as PD-L1 negative, and 17 cases as PD-L1 positive. Representative cases of IHC and ISH results are shown in Figure 1. The concordance between IHC and mRNA ISH results was near perfect at $95.5 \%(127 / 133)$, with a $\kappa$-coefficient of 0.824 (Table 2). No significant difference between the two methods was detected with the McNemarBowker test $(P=0.219)$.

\section{PD-L1 expression and its association with clinicopathological characteristics}

Expression of PD-L1 was significantly higher in male patients than in female patients $(P=0.019)$; in smokers than non-smokers $(P=0.002)$; and in solid, papillary, or micropapillary growth pattern tumors compared to acinar and lepidic growth pattern tumors $(P=0.000)$. No significant association was detected between expression of PD-L1 and patient age $(\geq 70$ versus $<70$ years, $P=1.000)$, tumor size $(\leq 3 \mathrm{~cm}$ versus $>3 \mathrm{~cm}, P=0.613$ ), clinical stage (I + II versus III $+\mathrm{IV}$, $P=0.067)$, pleural involvement $(P=0.553)$, or lymph node metastasis $(P=0.439)$.

\section{Prognostic significance of PD-L1 expression in lung adenocarcinoma}

In the 133 patients with lung adenocarcinoma, the median recurrence free survival (RFS) and overall survival (OS) times were 32.00 and 34.70 months, respectively. Forty-eight patients experienced recurrence at a median follow-up time of 14.00 months. Twenty-one patients died at a median follow up time of 22.60 months. KaplanMeier analysis revealed that PD-L1 expression was 
Table 2: Comparison of immunohistochemistry and in situ RNA detection methods for evaluation of PD-L1 expression

\begin{tabular}{lccccc}
\hline & & \multicolumn{2}{c}{ PD-L1 IHC } & \multirow{2}{*}{ Kappa } & \multirow{2}{*}{$\boldsymbol{p}$-value } \\
\cline { 2 - 5 } & & - & + & + & 0.219 \\
\hline PD-L1 & - & 110 & 5 & 0.824 & 0.219 \\
RNA ISH & + & 1 & 17 & & \\
\hline
\end{tabular}

Abbreviations: PD-L1, programmed cell death ligand 1; IHC, immunohistochemistry; ISH, in situ hybridization.

significantly associated with a shorter RFS $(P=0.000)$ and OS $(P=0.000)$ (Table 3, Figure 2). PD-L1 overexpression and advanced clinical stage were identified as independent prognostic factors in multivariate analyses (Table 4).

\section{DISCUSSION}

The clinical results show that monoclonal anti-PD-1/PD-L1 antibodies are powerful potential pharmaceutical therapy for advanced NSCLC. Careful selection of the targeted population is a prerequisite to protect patients from ineffective therapy and reduce side effects induced by the autoimmune system targeting the PD-1/PD-L1 axis. Preclinical data showed that PD-L1 expression is correlated with an increased likelihood of response to PD-L1 targeted therapy [10]. Establishing a reliable detection method to select the right patients is an urgent issue. Our study showed that the SP263 antibody is a good examination antibody, because of the high correlation of PD-L1 expression between the protein and mRNA level. PD-L1 is more highly expressed in male patients and smokers; in solid, papillary or micropapillary growth patterns compared to acinar and lepidic patterns; and its expression is an independent indicator of early disease recurrence and worse OS.

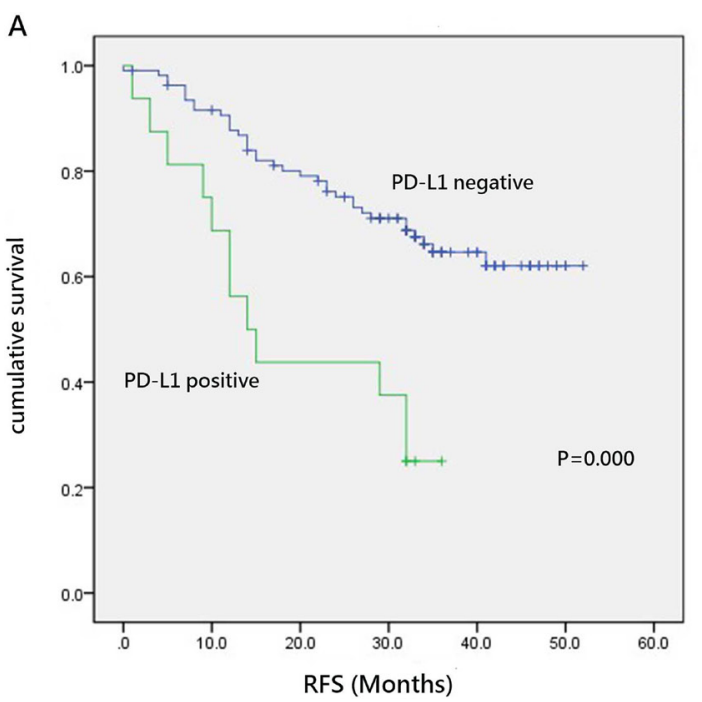

Evaluating human epidermal growth factor receptor-2 in breast cancer by IHC, which is economic and time-saving, has been successful. Efforts are being made to establish a method to evaluate PD-L1 expression by IHC. A multitude of detection PD-L1 IHC antibodies have been utilized, including the Ventana SP263 and SP142 clones, and the Dako 28-8 and 22C3 clones [11-13]. Various clones are currently being used in clinical trials to evaluate PD-L1 expression following use of different drugs. There is no consensus on the definition of a PD-L1 "positive" tumor, with different thresholds of cell expression used, e.g., $1 \%, 5 \%, 50 \%$, and $25 \%$. The lack of a standard examination method or a standard definition of a PD-L1 positive tumor following IHC staining is problematic. According to the central dogma of genetics, genes are first transcribed into mRNA and then translated into proteins. In the present study, the PD-L1 was detected and analyzed at the transcriptional level using mRNA ISH, and at the translational level using IHC. The concordance rate of the two methods was near perfect $(95.5 \%$; $\kappa$-coefficient, $0.824 ; P=0.219)$. A recent study compared and validated 6 commercially available PD-L1 monoclonal antibodies (SP142, E1L3N, 9A11, SP263, 22C3, and 28-8). Their results showed that all 6 antibodies had high levels of concordance $\left(R^{2}=0.76-0.99\right)$. They further suggested

B

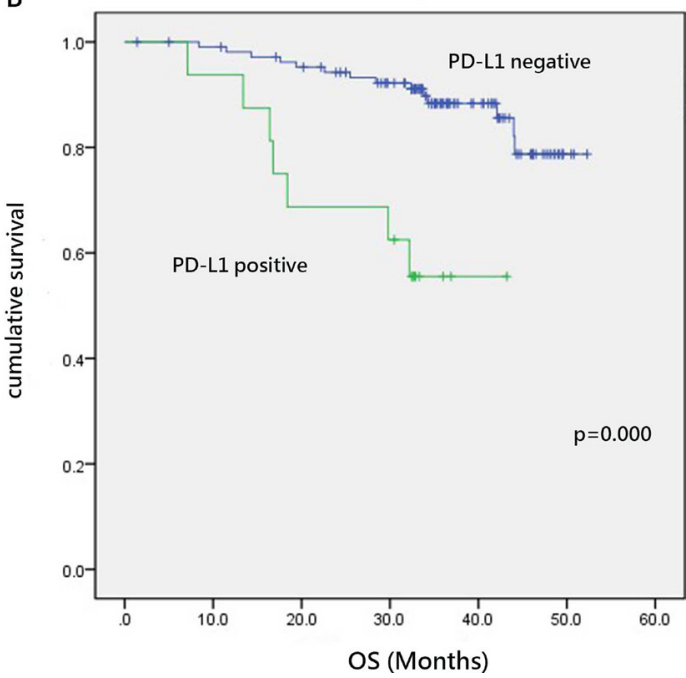

Figure 2: Prognostic significance of PD-L1 expression in lung adenocarcinoma. (A) Recurrence free survival in patients with positive or negative programmed cell death ligand (PD-L1) expression. (B) Overall survival in patients with positive or negative PD-L expression. 
Table 3: Univariate analysis for recurrence free survival and overall survival

\begin{tabular}{|c|c|c|c|c|}
\hline Variables & Median RFS (months) & $p$-value & Median OS (months) & $p$-value \\
\hline Age & & 0.178 & & 0.842 \\
\hline$\geq 70$ & 39.30 & & 45.17 & \\
\hline$<70$ & 36.04 & & 46.31 & \\
\hline Gender & & 0.047 & & 0.077 \\
\hline Female & 40.19 & & 42.82 & \\
\hline Male & 32.25 & & 47.99 & \\
\hline Smoking & & 0.138 & & 0.292 \\
\hline Smokers & 32.69 & & 42.98 & \\
\hline Non- smokers & 39.29 & & 47.39 & \\
\hline Tumor Size (cm) & & 0.309 & & 0.459 \\
\hline$>3$ & 34.14 & & 44.57 & \\
\hline$\leq 3$ & 39.08 & & 47.36 & \\
\hline Stage & & 0.000 & & 0.000 \\
\hline Early (I-II) & 42.58 & & 49.59 & \\
\hline Advanced (III-IV) & 28.50 & & 40.33 & \\
\hline Invasion of pleural & & 0.181 & & 0.408 \\
\hline Yes & 35.96 & & 46.00 & \\
\hline No & 40.25 & & 46.54 & \\
\hline Node metastasis & & 0.032 & & 0.066 \\
\hline Yes & 32.18 & & 42.55 & \\
\hline No & 40.31 & & 48.16 & \\
\hline $\begin{array}{l}\text { Post-operative } \\
\text { therapy }\end{array}$ & & 0.129 & & 0.188 \\
\hline Yes & 37.74 & & 38.11 & \\
\hline No & 35.81 & & 36.41 & \\
\hline PD-L1 expression & & 0.000 & & 0.000 \\
\hline Positive & 19.88 & & 32.61 & \\
\hline Negative & 39.74 & & 48.11 & \\
\hline
\end{tabular}

Abbreviations: PD-L1, programmed cell death ligand 1; RFS, recurrence free survival; OS, overall survival.

that previously described differences in PD-L1 expression in tissue are independent of the antibody used and likely attributable to tumor heterogeneity, assay- or platformspecific variables, or other factors [14]. Nowadays, the National Comprehensive Cancer Network guidelines have been updated to include the treatment of lung cancer by anti PD-L1 therapy, clinicians should choose different drugs according to the approved accompanied diagnostic methods before definitive conclusions can be drawn.

The PD-L1 expression rate in lung adenocarcinoma samples in our study was about $13 \%$. Previously reported expression rates of PD-L1 using different IHC antibodies range from $8 \%$ to $55 \%$ in lung adenocarcinoma or NSCLC patients [15-18]. This variation might be caused by the use of different antibodies, different interpretation criteria, and the lack of a consensus PD-L1 IHC method at present, or different population and tumor types. For example, in the Keynote-024 clinical trial which included 1653 patients, PD-L1 expression rate was $30.2 \%$ with a cut-off value of $50 \%$ or greater in NSCLC patients, which included adenocarcinoma and squamous cell carcinoma [19]. Our results are towards the lower limit of the previous results, mainly owing to ethnic group differences, and the relatively stricter evaluation criteria, i.e. only defining tumor positivity when more than $25 \%$ of the tumor cells were positive. In actuality, the clinical response rates in unselected patients across early trials have ranged from $10 \%$ to $20 \%$ in NSCLC $[6,8]$. Further validation of this examination method and the clinical response is needed to test if this is suitable for selecting targeted patients.

In our study, we observed significant correlation of PD-L1 expression with clinicopathological characteristics. PD-L1 expression is associated with smoking habits. 
Table 4: Multivariate analysis of prognostic factors of recurrence free survival and overall survival

\begin{tabular}{|c|c|c|c|c|}
\cline { 2 - 5 } \multicolumn{1}{c}{ Characteristic } & \multicolumn{2}{c}{ Recurrence free survival } & \multicolumn{1}{c}{ Overall survival } \\
\hline $\begin{array}{c}\text { PD-L1 expression } \\
\text { (Positive vs. negative) }\end{array}$ & $2.522(1.257-5.058)$ & 0.009 & $3.395(1.254-9.194)$ & 0.016 \\
\hline $\begin{array}{c}\text { Gender } \\
\text { (Female vs male) }\end{array}$ & $0.729(0.403-1.321)$ & 0.298 & $0.654(0.262-1.632)$ & 0.363 \\
\hline $\begin{array}{c}\text { Stage } \\
\text { (Advanced vs early) }\end{array}$ & $2.939(1.425-6.063)$ & 0.004 & $3.688(1.192-11.407)$ & 0.023 \\
\hline $\begin{array}{c}\text { Node metastasis } \\
\text { (Yes vs. no) }\end{array}$ & $0.881(0.434-1.789)$ & 0.725 & $0.976(0.349-2.735)$ & 0.964 \\
\hline
\end{tabular}

Abbreviations: PD-L1, programmed cell death ligand 1.

Smoking exposure may induce inflammatory as well as suppressive effects on the immune system [20]. Others have hypothesized that smoking-associated lung cancers have a higher mutational load, resulting in the creation of more tumor neoantigens and increased immunogenicity [21]. The results of the clinical trials showed that a history of smoking appears to impact the probability of response to anti-PD-1/PD-L1 monoclonal antibodies: the response rates in current/former smokers versus non/light smokers were associated with a stronger response to treatment $[11,13]$. Besides smoking, our results also showed that PD-L1 expression is more frequent in male patients. The main reason for this is that male patients $(31 / 53)$ were more likely to be smokers than the females (3/80). Other studies have also observed this correlation [22]. Previous studies have shown that overexpression of PD-L1 is much more common in poorly differentiated or higher pathological grades of lung adenocarcinoma [17, 23]. In our study, we also confirmed that papillary, micropapillary, and solid growth patterns are significantly associated with overexpression of PD-L1 compared to lepidic or acinar growth patterns. Besides these clinicopathological characteristics, others have also found that PD-L1 expression is associated with lymphovascular invasion, advanced lymph node stage, or pleural invasion, which we did not observe in our study [24].

Expression of PD-L1 was reported to be correlated with poor clinical outcomes in a number of human cancers, including lung, melanoma, breast, bladder, ovarian, pancreatic, esophageal adenocarcinoma, and kidney tumors [25]. In our study, we identified PDL1 as an independent indicator of early recurrence and shorter survival duration in lung adenocarcinoma. Others have also observed an association of PD-L1 with poorer prognosis in lung adenocarcinoma. For example, Zhang et al. discovered that in lung adenocarcinoma both PDL1 expression and PD-L2 expression were independent predictors of poor OS [26]. Chung et al. showed that PD-L1 and PD-L2 expression predicted poor prognosis for pulmonary adenocarcinoma [18]. The clinical trial results showed that PD-1 and PD-L1 blockade could prolong survival in patients with advanced lung cancer. All the above evidence indicated that overexpression of PD-L1 in tumor cells can help the tumor cells to escape the surveillance of $\mathrm{T}$ cells, in turn acquiring resistance and becoming more prone to proliferation or metastasis.

In conclusion, we have demonstrated that expression of PD-L1 was present in $13.5 \%$ of lung adenocarcinoma patients and was associated with a poorer prognosis. Further studies are warranted to confirm PD-L1 expression, and the therapeutic effect of PD-1/PD-L1 blockade, in clinical trials.

\section{MATERIALS AND METHODS}

\section{Patient information}

One hundred and thirty-three patients were enrolled in this study, and underwent a surgical operation with a final diagnosis of lung adenocarcinoma at Peking Union Medical College Hospital (PUMCH, Beijing, China) between January 2012 and December 2015. For poorly differentiated cases, additional immunostaining for Napsin A and thyroid transcription factor 1 (TTF-1) was performed to confirm the final results.

Clinical information for the patients was retrieved from the PUMCH digital database, including age, gender, smoking habit, clinical stage, treatment methods, RFS, and OS. Clinical stage was determined at the time of surgery, according to the American Joint Commission on Cancer (AJCC), 7th edition, tumor-node-metastasis staging system. RFS was defined as the time from operation to relapse or until the endpoint of the study. OS was calculated as the time from surgery to death or until the endpoint of the research, which was April 30th, 2016.

For each tumor sample, hematoxylin-eosin staining (HE) slides were all re-reviewed by two experienced pathologists to confirm the final diagnosis. The growth pattern of lung adenocarcinoma was defined according to the guidelines of the 2011 International Association for the Study of Lung Cancer/American Thoracic Society/ European Respiratory Society classification system that 
includes lepidic, acinar, papillary, micropapillary, and solid predominant patterns. Both pathologists had no knowledge of the clinical information or PD-L1 expression status of these cases during the review. Additionally, the following pathological characteristics were evaluated: tumor size, pleural invasion, and node metastasis status.

This study was approved by the Institutional Review Board of Peking Union Medical College Hospital. Informed consent was obtained from all patients before they underwent the operation.

\section{Tissue microarray construction}

The selected area of representative morphology was labeled on the HE slides. The corresponding formalinfixed paraffin-embedded (FFPE) primary tumor specimens were obtained from the Department of Pathology. A tissue microarray (TMA) construction machine (Tissue Array minicore, Mitogen, England) was used. Three core-tissue biopsies, $1.0 \mathrm{~mm}$ in diameter, were collected for each case.

\section{PD-L1 immunohistochemical examination}

The IHC study was performed on formalin-fixed, paraffin-embedded TMA sections, with a thickness of $4 \mu \mathrm{m}$, using standard autostaining protocols on a Ventana Benchmark ULTRA autostainer (Ventana Medical Systems, Inc., Tucson, AZ, USA). The PD-L1 antibody used in our study was SP263 (Roche Ventana, Tucson, AZ, USA). Tumors with positive membrane staining in more than $25 \%$ of the whole tumor were deemed positive, as suggested in a study by Ratcliffe et al. [27].

\section{PD-L1 mRNA detection by in situ hybridization}

For detection of PD-L1 expression, at the mRNA level, we used in situ hybridization (ISH). An RNAscope FFPE 2.0 HD detection kit (Brown, Advanced Cell Diagnostics, Hayward, CA, USA) was used according to the manufacturer's instructions. Briefly, $5 \mu \mathrm{m}$-sections were deparaffinized, boiled with pre-amplification reagent for 15 minutes and submitted to protease digestion followed by hybridization for $2 \mathrm{~h}$ with a mixture containing target probes against human PD-L1, ubiquitin C (UBC) as a positive control, and the bacterial gene DapB as a negative control. Hybridization signals were detected with 3,3'-diaminobenzidine. Positive staining was indicated by brown punctate dots in the cytoplasm or nucleus. PD-L1 mRNA expression levels were categorized into 5 grades according to the manufacture's scoring guideline: score 0 , no staining or $<1$ dot per cell; score $1,1-3$ dots per cell (visible at 20-40X); score 2, 4-10 dots per cell (visible at $20-40 \mathrm{X})$; score $3,>10$ dots per cell and $<10 \%$ positive cells have dot clusters (visible at 20-40X); score 4, > 10 dots per cell and $>10 \%$ positive cells have dot clusters (visible at 20-40X). We grouped score 0, 1, 2 as negative, 3 and 4 as positive.

\section{Statistical analysis}

The relationship between PD-L1 expression and clinicopathological characteristics was analyzed using the chi-squared test. Survival analysis was calculated by the Kaplan-Meier method, the log rank test was used to compare the difference of two groups, and multivariate analysis using the Cox regression model was conducted to analyze the related clinicopathological features. All tests were 2 -sided. $\mathrm{P}<0.05$ was considered statistically significant. The statistical analyses were performed using SPSS software (version 21; SPSS, Chicago, IL, USA).

For analysis of concordance between the results of IHC and RNA ISH, the kappa value was calculated. The significance of the $\kappa$-value was considered as follows: value $\leq 0.40$, poor to fair concordance; 0.41-0.60, moderate concordance; $0.61-0.80$, substantial concordance; 0.81-1.00, almost perfect concordance.

\section{Abbreviations}

NSCLC: non-small cell lung cancer; EGFR: epidermal growth factor receptor; ALK: anaplastic lymphoma kinase; TILs: tumor-infiltrating lymphocytes; Programmed cell death protein 1: PD-1: Programmed cell death protein 1; PD-L1: Programmed cell death ligand 1; IHC: Immunohistochemistry; RFS: Recurrence free survival; OS: Overall survival; FFPE: Formalin-fixed paraffin-embedded; TMA: Tissue microarray.

\section{ACKNOWLEDGMENTS}

The authors thank the Histology Laboratory at Peking Union Medical College Hospital performed immunohistochemical studies of these cases; technician Zhang Yuhan for preparing the TMA blocks.

\section{CONFLICTS OF INTEREST}

The authors have no conflicts of interest to declare.

\section{Authors'contributions}

Z.X and L.Z.Y conceived the study. S.X.H and S.J evaluated the IHC and ISH results. L.Y.F finished the IHC examinations. W.S.F carried out the ISH examinations. L.Y.Y prepared the TMA slides. W.J.H revised the manuscript.

\section{REFERENCES}

1. Saito M, Shiraishi K, Kunitoh H, Takenoshita S, Yokota J, Kohno T. Gene aberrations for precision medicine against lung adenocarcinoma. Cancer Sci. 2016; 107:713-20. doi: 10.1111/cas.12941. 
2. Devarakonda S, Morgensztern D, Govindan R. Genomic alterations in lung adenocarcinoma. Lancet Oncol. 2015; 16: e342-51. doi: 10.1016/s1470-2045(15)00077-7.

3. Yu HA, Tian SK, Drilon AE, Borsu L, Riely GJ, Arcila ME, Ladanyi M. Acquired Resistance of EGFR-Mutant Lung Cancer to a T790M-Specific EGFR Inhibitor: Emergence of a Third Mutation (C797S) in the EGFR Tyrosine Kinase Domain. JAMA Oncol. 2015; 1:982-4. doi: 10.1001/ jamaoncol.2015.1066.

4. Xu Y, Liu H, Chen J, Zhou Q. Acquired resistance of lung adenocarcinoma to EGFR-tyrosine kinase inhibitors gefitinib and erlotinib. Cancer Biol Ther. 2010; 9:572-82.

5. Kumarakulasinghe NB, van Zanwijk N, Soo RA. Molecular targeted therapy in the treatment of advanced stage nonsmall cell lung cancer (NSCLC). Respirology. 2015; 20:370-8. doi: 10.1111/resp.12490.

6. Brahmer JR, Tykodi SS, Chow LQ, Hwu WJ, Topalian SL, Hwu P, Drake CG, Camacho LH, Kauh J, Odunsi K, Pitot HC, Hamid O, Bhatia S, et al. Safety and activity of anti-PD-L1 antibody in patients with advanced cancer. N Engl J Med. 2012; 366:2455-65. doi: 10.1056/NEJMoa1200694.

7. Califano R, Kerr K, Morgan RD, Russo GL, Garassino M, Morgillo F, Rossi A. Immune Checkpoint Blockade: A New Era for Non-Small Cell Lung Cancer. Curr Oncol Rep. 2016; 18: 59. doi: 10.1007/s11912-016-0544-7.

8. Topalian SL, Hodi FS, Brahmer JR, Gettinger SN, Smith DC, McDermott DF, Powderly JD, Carvajal RD, Sosman JA, Atkins MB, Leming PD, Spigel DR, Antonia SJ, et al. Safety, activity, and immune correlates of anti-PD-1 antibody in cancer. N Engl J Med. 2012; 366:2443-54. doi: 10.1056/NEJMoa1200690.

9. Sznol M, Chen L. Antagonist antibodies to PD-1 and B7-H1 (PD-L1) in the treatment of advanced human cancer-response. Clin Cancer Res. 2013; 19: 5542. doi: 10.1158/1078-0432.ccr-13-2234.

10. Pardoll DM. The blockade of immune checkpoints in cancer immunotherapy. Nat Rev Cancer. 2012; 12:252-64. doi: 10.1038/nrc3239.

11. Gettinger SN, Horn L, Gandhi L, Spigel DR, Antonia SJ, Rizvi NA, Powderly JD, Heist RS, Carvajal RD, Jackman DM, Sequist LV, Smith DC, Leming P, et al. Overall Survival and Long-Term Safety of Nivolumab (Anti-Programmed Death 1 Antibody, BMS-936558, ONO4538) in Patients With Previously Treated Advanced NonSmall-Cell Lung Cancer. J Clin Oncol. 2015; 33:2004-12. doi: $10.1200 /$ jco.2014.58.3708.

12. Garon EB, Rizvi NA, Hui R, Leighl N, Balmanoukian AS, Eder JP, Patnaik A, Aggarwal C, Gubens M, Horn L, Carcereny E, Ahn MJ, Felip E, et al. Pembrolizumab for the treatment of non-small-cell lung cancer. N Engl J Med. 2015; 372:2018-28. doi: 10.1056/NEJMoa1501824.

13. Herbst RS, Soria JC, Kowanetz M, Fine GD, Hamid O, Gordon MS, Sosman JA, McDermott DF, Powderly JD, Gettinger SN, Kohrt HE, Horn L, Lawrence DP, et al. Predictive correlates of response to the anti-PD-L1 antibody
MPDL3280A in cancer patients. Nature. 2014; 515:563-7. doi: 10.1038/nature14011.

14. Gaule P, Smithy JW, Toki M, Rehman J, Patell-Socha F, Cougot D, Collin P, Morrill P, Neumeister V, Rimm DL. A Quantitative Comparison of Antibodies to Programmed Cell Death 1 Ligand 1. JAMA Oncol. 2016. doi: 10.1001/ jamaoncol.2016.3015.

15. Azuma K, Ota K, Kawahara A, Hattori S, Iwama E, Harada T, Matsumoto K, Takayama K, Takamori S, Kage M, Hoshino T, Nakanishi Y, Okamoto I. Association of PD-L1 overexpression with activating EGFR mutations in surgically resected nonsmall-cell lung cancer. Ann Oncol. 2014; 25:1935-40. doi: 10.1093/annonc/mdu242.

16. D’Incecco A, Andreozzi M, Ludovini V, Rossi E, Capodanno A, Landi L, Tibaldi C, Minuti G, Salvini J, Coppi E, Chella A, Fontanini G, Filice ME, et al. PD-1 and PD-L1 expression in molecularly selected non-small-cell lung cancer patients. Br J Cancer. 2015; 112:95-102. doi: 10.1038/bjc.2014.555.

17. Yang CY, Lin MW, Chang YL, Wu CT, Yang PC. Programmed cell death-ligand 1 expression in surgically resected stage I pulmonary adenocarcinoma and its correlation with driver mutations and clinical outcomes. Eur J Cancer. 2014; 50:1361-9. doi: 10.1016/j.ejca.2014.01.018.

18. Chung DH, Kerr KM, Tsao MS, Nicholson AG, Yatabe Y, Wistuba, II, Hirsch FR. Programmed Death-Ligand 1 Immunohistochemistry in Lung Cancer: In what state is this art? Mod Pathol. 2015; 10:985-9. doi: 10.1038/ modpathol.2015.6310.1097/jto.0000000000000526.

19. Reck M, Rodriguez-Abreu D, Robinson AG, Hui R, Csoszi T, Fulop A, Gottfried M, Peled N, Tafreshi A, Cuffe S, O'Brien M, Rao S, Hotta K, et al. Pembrolizumab versus Chemotherapy for PD-L1-Positive Non-Small-Cell Lung Cancer. N Engl J Med. 2016; 375:1823-33. doi: 10.1056/ NEJMoa1606774.

20. Vassallo R, Tamada K, Lau JS, Kroening PR, Chen L. Cigarette smoke extract suppresses human dendritic cell function leading to preferential induction of Th-2 priming. J Immunol. 2005; 175:2684-91.

21. Lawrence MS, Stojanov P, Polak P, Kryukov GV, Cibulskis K, Sivachenko A, Carter SL, Stewart C, Mermel CH, Roberts SA, Kiezun A, Hammerman PS, McKenna A, et al. Mutational heterogeneity in cancer and the search for new cancer-associated genes. Nature. 2013; 499:214-8. doi: 10.1038/nature12213.

22. Cha YJ, Kim HR, Lee CY, Cho BC, Shim HS. Clinicopathological and prognostic significance of programmed cell death ligand-1 expression in lung adenocarcinoma and its relationship with p53 status. Lung Cancer. 2016; 97:73-80. doi: 10.1016/j. lungcan.2016.05.001.

23. Koh J, Go H, Keam B, Kim MY, Nam SJ, Kim TM, Lee SH, Min HS, Kim YT, Kim DW, Jeon YK, Chung DH. Clinicopathologic analysis of programmed cell death-1 and programmed cell death-ligand 1 and 2 expressions in 
pulmonary adenocarcinoma: comparison with histology and driver oncogenic alteration status. Mod Pathol. 2015; 28:1154-66. doi: 10.1038/modpathol.2015.63.

24. Takada K, Okamoto T, Shoji F, Shimokawa M, Akamine T, Takamori S, Katsura M, Suzuki Y, Fujishita T, Toyokawa G, Morodomi Y, Okano S, Oda Y, et al. Clinical Significance of PD-L1 Protein Expression in Surgically Resected Primary Lung Adenocarcinoma. J Thorac Oncol. 2016; 11:1879-90. doi: 10.1016/j.jtho.2016.06.006.

25. Zou W, Chen L. Inhibitory B7-family molecules in the tumour microenvironment. Nat Rev Immunol. 2008; 8:467-77. doi: $10.1038 /$ nri2326.
26. Zhang Y, Wang L, Li Y, Pan Y, Wang R, Hu H, Li H, Luo X, Ye T, Sun Y, Chen H. Protein expression of programmed death 1 ligand 1 and ligand 2 independently predict poor prognosis in surgically resected lung adenocarcinoma. Onco Targets Ther. 2014; 7:567-73. doi: 10.2147/ott.s59959.

27. Marianne J. Ratcliffe, Alan Sharpe, Anita Midha, Craig Barker, Marietta Scott, Paul Scorer, Walker. J. (2016). A Comparative Study of PD-L1 Diagnostic Assays and the Classification of Patients as PD-L1 Positive and PDL1 Negative. American Association for Cancer Research (AACR) Annual Meeting (New Orleans, LA, USA. 